\title{
Etiology and Complications of Portal Vein Thrombosis
}

\author{
Jonel Trebicka Christian P. Strassburg \\ Department of Internal Medicine I, University of Bonn, Bonn, Germany
}

\section{Keywords}

Portal vein thrombosis - Malignancy - Cirrhosis .

Myeloproliferative neoplasm · Thrombophilia

\section{Summary}

Background: Portal venous occlusion represents a disorder with considerable clinical relevance. The underlying causes of portal vein thrombosis (PVT) are frequently multifactorial and include malignancies, progressive chronic liver diseases, processes localized to the epigastrium and hepatobiliary system, and acquired as well as inherited thrombophilia. The three main categorical groups are malignant thrombosis, cirrhotic PVT, and non-malignant, non-cirrhotic PVT. Methods: Review of the literature. Results: The site, the extent, its chronicity, and the course of thromboses characterize a relatively heterogeneous clinical presentation and the ensuing complications in affected patients. While the occlusion of the extrahepatic portal and splenic vein likely provokes mainly complications related to portal hypertension, mesenteric venous obstruction shows a high rate of complications and mortality due to intestinal infarction. Especially in patients with liver cirrhosis, special care is warranted with regard to PVTs due to their pathogenetic role and influence on patient survival. Conclusion: This article aims to summarize the current opinion on etiologies, risk factors, and complications of this heterogeneous condition in adults.

\section{Introduction}

Obstruction of the portal vein and its tributaries is capable of leading to serious adverse short- and/or long-term events in the affected patients. The tributary portal venous system is

\author{
Schlüsselwörter \\ Pfortaderthrombose $\cdot$ Malignome $\cdot$ Zirrhose . \\ Myeloproliferative Neoplasien - Thrombophilie
}

\section{Zusammenfassung}

Hintergrund: Die Pfortaderthrombose ist ein relevantes klinisches Ereignis mit einer heterogenen und häufig multifaktoriellen Ätiologie. Die zugrunde liegenden Ursachen reichen von Malignomen über chronische Lebererkrankungen und periportale Prozesse bis hin zu erworbener und vererbter Thrombophilie. Als ätiologische Hauptgruppen werden die malignen, die zirrhotischen und die nichtmalignen, nichtzirrhotischen Thrombosen unterschieden. Methoden: Literaturübersicht. Ergebnisse: Die genaue Lokalisation, die Ausdehnung und der Verlauf der Thrombose entscheiden über die oft heterogenen klinischen Verläufe und Komplikationen bei diesen Patienten. Während die Thrombose der extrahepatischen Pfortader und Milzvene eher zu Komplikationen verbunden mit portalem Hypertonus führen, können Thrombosen der mesenterialen Venen eine hohe Rate an Komplikationen und Mortalität aufgrund einer mesenterialen Infarzierung bedingen. Vor allem bei Patienten mit einer Leberzirrhose ist besondere Vorsicht geboten, da die Pfortaderthrombose eine pathogenetische Rolle spielt und das Überleben beeinflusst. Schlussfolgerung: Diese Übersichtsarbeit fasst die derzeitige Meinung bezüglich der Ätiologie, der Risikofaktoren und der Komplikationen dieser heterogenen Erkrankung bei Erwachsenen zusammen.

anatomically in close proximity (fig. 1) [1]; nevertheless, the different sites and the heterogeneous causes of venous obstruction make the possible resulting complications clinically difficult and complicated to treat [2-4]. While the occlusion of the extrahepatic portal and splenic vein can provoke compli-

\section{KARGER \\ Fax +497614520714 Information@Karger.com} www.karger.com

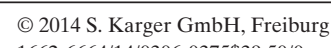

PD Dr. Dr. Jonel Trebicka

Medizinische Klinik und Poliklinik I

Universitätsklinikum Bonn

Sigmund-Freud-Straße 25, 53127 Bonn, Germany

jonel.trebicka@ukb.uni-bonn.de 
Fig. 1. Splanchnic venous thrombus location. Percentages and location of isothrombosis are presented whereas the percentage of multiple vein thrombosis is summarized [1]. lated venous segment

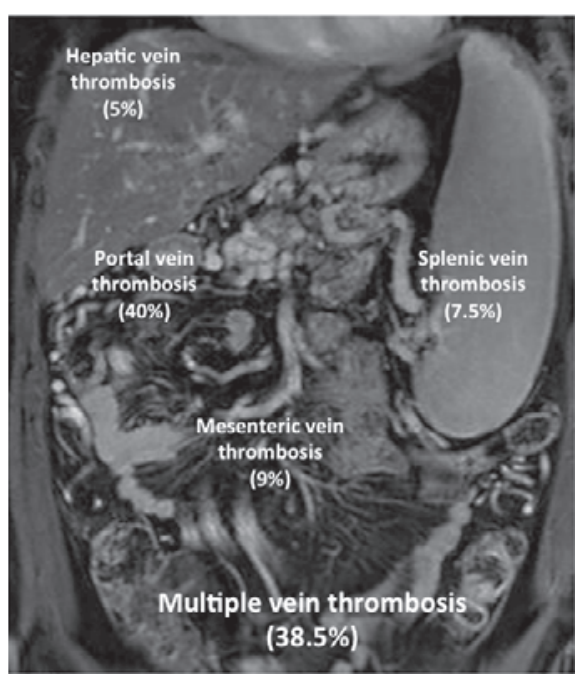

cations mainly related to portal hypertension [1-3], the mesenteric vein obstruction shows a high rate of complications and mortality due to intestinal infarction $[1,5]$.

The occurrence of this condition is probably underestimated given the fact that the clinical appearance can vary from asymptomatic patients incidentally diagnosed to patients with severe complications $[1,3,6]$. The technical evolution and the increasing use and availability of appropriate diagnostic tools have profoundly changed the epidemiology of portal vein thrombosis (PVT): from four cases per one million people in 1991 based on hospital registry data [7] this incidence has increased to over $1 \%$ in consecutive autopsy series [6] and to $1.74 \%$ in computed tomography (CT) analyses in 2012 [8].

From a pathophysiological point of view, PVT is a consequence of the so-called 'Virchow's triad', which comprises venous stasis, endothelial injury, and hypercoagulopathy [2]. For this reason, the underlying cause of PVT includes malignancy, chronic liver diseases, local inflammatory processes, systemic disorders including myeloproliferative disorders, and thrombophilia. In a high percentage of patients two or more risk factors are present $[2,4,9]$. This article summarizes our current knowledge about etiology, risk factors, and complications of this heterogeneous condition in adults. The diagnostic procedures and therapeutic management are discussed elsewhere within this special issue.

\section{Etiological Facts and Risk Factors}

In population studies, the cohort of patients with occlusion in the portal tributary system can be divided into three similarly large subcohorts of major etiologies: i) malignant thrombosis mainly due to gastrointestinal, hepatobiliary, or pancreatic cancer, ii) chronic liver diseases, especially liver cirrhosis with portal hypertension, and iii) non-malignant, non-cirrhotic PVT $[1-3,6]$. While the underlying disease determines the natural history and outcome of patients in the case of ma- lignant thrombosis, the two other groups of patients are characterized by an outcome influenced by PVT $[2,10]$. Furthermore, non-malignant, non-cirrhotic PVT has often been described as an entity of its own, leading to non-cirrhotic portal hypertension, which represents more of a consequence than a complication of another disease [4]. For this reason, the three large etiologic categories are described separately in the following.

\section{Malignant Portal Vein Thrombosis}

In general, malignant PVT is associated with the progression of a malignant disease. A thrombosis in the portal system defines vascular invasion of the malignant entity and thereby the spreading to the blood system. Data are scarce on this etiology regarding splanchnic thrombosis; however, primary hepatobiliary cancer, metastatic cancer, and secondary malignancy of the hepatobiliary region can be distinguished $[1,5$, 6]. In a large retrospective study including 23,796 consecutive autopsies ( $84 \%$ of all in-hospital deaths) in the Malmö city population [6], the majority of thromboses occurred due to secondary malignancies of the hepatobiliary region (table 1). In contrast, detailed statistics revealed that PVT was present in $14.3 \%$ of the patients with primary hepatic cancer and concomitant cirrhosis as well as in $11.5 \%$ of the patients with pancreatic carcinoma (table 2). Complications of portal hypertension due to PVT, however, were rather low in cancer patients without cirrhosis in this study, e.g. gastrointestinal bleeding occurred in only $14 \%$ compared to $59 \%$ in cirrhotics without cancer [6]. Despite these findings, this study is limited because of patient selection (only in-hospital deaths). Other reviews and smaller studies have confirmed these data regarding etiology and distribution of malignant thrombosis, though [2].

\section{Cirrhotic Portal Vein Thrombosis}

Liver cirrhosis is a causal factor in approximately one third of all patients with PVT $[2,6,11-13]$. In patients with compensated cirrhosis, the prevalence is approximately $1 \%$ [14] and, thus, similar to the prevalence reported in the total population $[6,8]$. The prevalence of PVT rises to $8-25 \%$ in patients awaiting liver transplantation $[2,13,15]$ and is diagnosed in $50-70 \%$ in explanted cirrhotic livers during liver transplantation $[15,16]$. Interestingly, in a systematic review of 885 patients who underwent liver transplantation, the prevalence of PVT was $3.6 \%$ in primary sclerosing cholangitis, $8 \%$ in primary biliary cirrhosis, and $16 \%$ in alcoholic and $\mathrm{HBV}$ (hepatitis B virus)-induced cirrhosis but amounted to $36 \%$ in patients with liver cirrhosis and hepatocellular carcinoma $[2,13,17]$.

Reasons for the high incidence of PVT in advanced cirrhosis might be the simultaneous presence and effect of the three components of the Virchow's triad: venous stasis, endothelial injury, and hypercoagulopathy $[2,18]$.

Venous stasis is common in full-blown cirrhosis and seems to be an important predictor for PVT [19-21] because fibrotic 
Table 1. Prevalence of patients with PVT $(\mathrm{n}=254)$ of the conditions known to be major causes [6]

\begin{tabular}{lcc}
\hline Patient category & $\begin{array}{l}\mathrm{n}(\%) \text { of PVT } \\
\text { patients }\end{array}$ & $\begin{array}{l}\mathrm{n}(\%) \text { within risk } \\
\text { category }\end{array}$ \\
\hline Cirrhosis $^{\mathrm{a}}$ & $72(28)$ & \\
$\quad$ With primary hepatic cancer & & $26(36)$ \\
$\quad$ Without primary hepatic cancer & $59(23)$ & $46(64)$ \\
Primary hepatobiliary cancer & \\
$\quad$ Hepatic carcinoma & & $38(64)$ \\
$\quad$ Biliary/gall bladder carcinoma & $111(44)$ & $21(36)$ \\
Secondary malignancy of the hepatobiliary region ${ }^{\mathrm{a}}$ & & $47(42)$ \\
$\quad$ Pancreatic carcinoma & & $20(18)$ \\
$\quad$ Gastric carcinoma & & $71(10)$ \\
$\quad$ Colorectal carcinoma & & $7(6)$ \\
$\quad$ Lung cancer & & $21(19)^{\mathrm{a}}$ \\
$\quad$ Malignant lymphoma & $7(3)$ & \\
$\quad$ Other primary cancer & $25(10)$ & \\
Myeloproliferative disorders & \\
Major abdominal infection/inflammation & \\
No cause identified & $36(14)$ & \\
\hline${ }^{a}$ Categories are not mutually exclusive. & &
\end{tabular}

Table 2. Prevalence and relative risk (OR) of PVT in relation to disease condition with major risk of PVT [6]

\begin{tabular}{lccc}
\hline Patient category & $\mathrm{n}(\%)$ & PVT $(\%)$ & OR (95\% CI) \\
\hline Cirrhosis & $1,193(5.0)$ & $72(6.0)$ & $7.9(6.0-10.5)$ \\
With primary hepatic cancer & 182 & $26(14.3)$ & $17.1(11.1-26.4)$ \\
$\quad$ Without primary hepatic cancer & 1,011 & $46(4.5)$ & $5.2(3.7-7.2)$ \\
Primary hepatobiliary cancer & $698(2.9)$ & $59(8.5)$ & $10.8(8.0-14.7)$ \\
Hepatic carcinoma & 392 & $38(9.7)$ & $11.5(8.0-16.5)$ \\
With cirrhosis & 182 & $26(14.3)$ & $17.1(11.1-26.4)$ \\
Without cirrhosis & 210 & $12(5.7)$ & $5.8(3.2-10.6)$ \\
Biliary/gall bladder carcinoma & 313 & $21(6.7)$ & $7.2(4.5-11.4)$ \\
Secondary malignancy of the hepatobiliary region & $3,446(14.5)$ & $113(3.3)$ & $4.9(3.8-6.2)$ \\
Pancreatic carcinoma & 312 & $36(11.5)$ & $13.9(9.6-20.2)$ \\
Gastric carcinoma & 316 & $18(5.6)$ & $5.9(3.6-9.7)$ \\
Colorectal carcinoma & 637 & $13(2.0)$ & $2.0(1.1-3.5)$ \\
Myeloproliferative disorders & $231(1.0)$ & $7(2.0)$ & $3.0(1.4-6.3)$ \\
All patients & 23,796 & $254(1.0)$ & \\
\hline OR = Odds ratio; CI = confidence interval. & & & \\
\hline
\end{tabular}

tissue deposition and dynamic intrahepatic resistance increase and lead to a lower velocity of portal blood flow [22]. Portal venous congestion increases vascular shear stress with consecutive endothelial injury and vascular dysfunction, which is associated with an overproduction of vasodilators (e.g. nitric oxide) and additionally leads to dysfunctional vasoconstrictor pathways [23]. Together, these two mechanisms result in splanchnic vasodilation with hyperperfusion, which in turn aggravates portal hypertension and portal venous congestion. In cirrhotic patients, the risk for PVT increases when portal venous flow velocity falls below $15 \mathrm{~cm} / \mathrm{s}$ [12, 13, 24, 25].

Additionally, cirrhosis is characterized by a hypercoagulable state despite the fact that the international normalized ratio (INR) in advanced cirrhosis is often increased [2, 18]. In cirrhosis, the physiological balance of pro- and anticoagula- tory proteins is disturbed. Indeed, not only the synthesis of the procoagulatory proteins is impaired but also the synthesis of anticoagulatory proteins is decreased [26, 27]. Thus, the physiological balance of coagulation is easily tilted either towards bleeding or towards thrombosis [25, 26, 28]. Increased levels of factor VIII (procoagulant), which increase with a rising Child score, combined with lower levels of protein C (anticoagulant) are believed to be responsible for hypercoagulation. This imbalance and especially the exceeding levels of factor VIII explain the increasing incidence of PVT with worsening liver function in cirrhosis [29].

Further risk factors for PVT have been suggested and include lower platelet count, recurrent decompensation, previous bleeding episodes, and infections [2]. These factors predispose and facilitate endotoxin flooding into the portal ve- 
Table 3. Inherited and acquired risk factors for acute PVT [4, 32]

\begin{tabular}{lcc}
\hline Underlying disorder & n tested & positive \\
\hline Myeloproliferative neoplasm & 102 & 21 \\
JAK2-positive & 82 & 16 \\
Antiphospholipid syndrome & 90 & 8 \\
Paroxysmal nocturnal hemoglobinuria & 39 & 0 \\
Factor V Leiden & 94 & 3 \\
Factor II mutation & 98 & 14 \\
Protein C deficiency & 86 & 1 \\
Protein S deficiency & 85 & 5 \\
Antithrombin deficiency & 89 & 2 \\
Hyperhomocysteinemia & 69 & 11 \\
Recent pregnancy & 50 & 1 \\
Recent oral contraceptive use & 50 & 44 \\
Systemic disease & 101 & 4 \\
More than one risk factor & & 52 \\
Local factor $^{\mathrm{b}}$ & 102 & 21 \\
\hline
\end{tabular}

ancluding connective tissue disease, inflammatory bowel disease, Behcet's disease, HIV infection.

${ }^{\mathrm{b}}$ Acute pancreatitis, intra-abdominal focus of infection, or abdominal trauma.

nous system, which is capable of activating the coagulation cascade and may lead to thrombus formation [30]. In contrast, inherited thrombophilias (i.e. G20210A prothrombin mutation, factor V Leiden mutation, TT677 MTHFR gene mutation) play a minor pathogenic role in cirrhotic PVT [2, 18, 31].

These data, hypotheses, and studies might explain the observation that in $8-16 \%$ patients with end-stage liver disease on a waiting list for liver transplantation de novo PVT develops within 12 months of follow-up [13].

\section{Non-Malignant, Non-Cirrhotic Portal Vein Thrombosis}

PVT in the absence of malignancy and cirrhosis is mainly due to systemic prothrombogenetic conditions and local factors $[4,32]$ (table 3 ). Among these factors, myeloproliferative neoplasias appear as a major cause in $20-50 \%$ of the patients with PVT [10, 32]. In a meta-analysis of 855 patients with PVT, myeloproliferative neoplasms were present in about $30 \%$ of the patients, and JAK 2 V617F mutations were found in $28 \%$ of the cohort [9]. First data on the role of the recently described novel mutation in the calreticulin gene for myeloproliferative neoplasm does not seem to play an important role in patients with PVT [33].

Inherited and acquired thrombophilias (table 3) appear to play a more important role in patients with Budd-Chiari syndrome than in PVT [2]. However, in almost half of the patients with PVT more than one risk factor or cause was present [4]. Therefore, investigations to identify a prothrombotic risk factor in patients with local causes for the PVT and vice versa are necessary and recommended $[2,4]$.

\section{Clinical Findings and Complications of Portal Vein Thrombosis}

The site (fig. 1), extent (partial or complete), chronicity (acute or chronic), and course (progressive or self-resolving) of thromboses determine their clinical presentation as well as their complications in affected patients [2]. While partial PVT is usually discovered incidentally by routine diagnostics and remains clinically silent, the complete occlusion of the vein (90-100\% of the lumen) is associated with abdominal and/or lumbar pain characterized by sudden onset or progressive development over the course of a few days [18]. Acute and complete thrombosis is usually associated with intestinal congestion and occasionally with non-sanguineous diarrhea $[12,34,35]$. In this case, a diffuse and homogeneous thickening of the intestinal wall may be present in imaging studies [36].

The most feared complication is intestinal infarction with a mortality of $20-60 \%$, leading to extended resections with a high risk of postoperative complications [4, 5, 37-41]. In contrast to intestinal congestion, infarction often presents with persistent pain, hematochezia, guarding, contracture, ascites, or multiorgan failure with metabolic acidosis [4]. In a usually urgently performed CT scan, the major findings can include hypo- or hyperattenuated wall thickening, dilatations, abnormal or absent wall enhancement, mesenteric stranding, ascites, pneumatosis, and portal venous gas [4, 42]. It is important to emphasize that this complication is usually found when the mesenteric veins are involved [2, 4]. Interestingly, in a retrospective analysis performed in patients with mesenteric vein thrombosis, a lack of performing CT studies was associated with an increased mortality [5].

\section{Complications due to Portal Hypertension}

The majority of complications of long-standing PVT are due to portal hypertension $[2,4]$. Collateralization of the portal vein might lead to the development of the so-called portal cavernoma [4]. However, portosystemic shunting can also develop, since these cavernous collaterals may not sufficiently drain the portal blood flow, and portal pressure is not sufficiently decreased. This usually presents as de novo appearance and/or progression of gastric or esophageal varices and may be complicated by bleeding [4, 35, 43, 44]. Bleeding due to PVT occurs about 100 times more often in patients with cirrhosis $[45,46]$. In comparison, cirrhotic patients with PVT exhibit a $10 \%$ higher bleeding rate compared to cirrhotic patients without PVT [13]. Therefore, cirrhotic portal hypertension is a major risk factor for bleeding, and PVT in cirrhotic patients considerably aggravates this problem.

Another but less frequent complication of collateral vessel formation is the pronounced portosystemic shunting in some patients, which leads to subclinical hepatic encephalopathy [4, $35,43,44]$. Furthermore, the development of collaterals can deform the biliary tree and may thus lead to a so-called portal 
biliopathy or cholangiopathy [4, 47-49], which is present in almost all patients although only few develop secondary biliary complications [49].

\section{Complications due to Decompensation of Chronic Liver Disease}

One frequent complication is the recurrence of thrombosis, which can maintain or aggravate a critical clinical situation of the affected patient $[4,35,44]$. Especially in cirrhotic patients, PVT is a common cause of decompensation $[2,11]$. In the literature, the hypothesis of hepatic parenchymal extinction as a consequence of microthrombi into the intrahepatic vascular tree with consecutive fibrotic remodeling of liver tissue has been extensively discussed but not conclusively proven in detail to date $[2,11,50,51]$. Apart from this hypothesis, coagulation activity and progressive liver fibrosis have been shown to be linked to each other [11]. Provocatively speaking, the development of an extrahepatic PVT can be regarded as the natural history of liver cirrhosis [11]. However, cirrhotic patients with an obstruction of the portal venous system show an increased mortality [52]. These patients exhibit a mortality rate similar to patients with a MELD (model for end-stage liver disease) score of 26, even though their laboratory MELD was calculated to be 12 [52]. Furthermore, the posttransplant survival is decreased in patients with PVT $[52,53]$, which appears to be dependent on the extent of the thrombosis [53]. Taken together, PVT must be carefully considered during the diagnostic and therapeutic decision making in cirrhotic patients as it profoundly influences survival.

\section{Conclusions}

Portal vein occlusion is a clinically relevant disorder which should be rapidly diagnosed and which requires interdisciplinary collaboration in order to prevent or treat invariably ensuing complications. The underlying cause should be investigated, and other causes should be excluded. Multifactorial causes are frequent. Particularly patients with liver cirrhosis require special care with regard to PVT since this is linked to the pathophysiology of the disease and thus influences patient survival.

\section{Disclosure Statement}

The authors have no conflict of interest.

\section{References}

$>_{1}$ Thatipelli MR, McBane RD, Hodge DO, Wysokinski WE: Survival and recurrence in patients with splanchnic vein thromboses. Clin Gastroenterol Hepatol 2010;8:200-205.

2 Pieri G, Theocharidou E, Burroughs AK: Liver in haematological disorders. Best Pract Res Clin Gastroenterol 2013;27:513-530.

3 Riva N, Donadini MP, Dentali F, Squizzato A, Ageno W: Clinical approach to splanchnic vein thrombosis: risk factors and treatment. Thromb Res 2012;130(suppl 1):S1-3.

$\checkmark 4$ Plessier A, Rautou PE, Valla DC: Management of hepatic vascular diseases. J Hepatol 2012;56(suppl 1):S25-38.

5 Acosta S, Alhadad A, Svensson P, Ekberg O: Epidemiology, risk and prognostic factors in mesenteric venous thrombosis. Br J Surg 2008;95:1245-1251.

6 Ogren M, Bergqvist D, Bjorck M, Acosta S, Eriksson H, Sternby NH: Portal vein thrombosis: prevalence, patient characteristics and lifetime risk: a population study based on 23,796 consecutive autopsies. World J Gastroenterol 2006;12:2115-2119.

7 Almdal TP, Sorensen TI: Incidence of parenchymal liver diseases in Denmark, 1981 to 1985: analysis of hospitalization registry data. The Danish Association for the Study of the Liver. Hepatology 1991;13:650-655.

$>8$ Ageno W, Squizzato A, Togna A, Magistrali F, Mangini M, Fugazzola C, Dentali F: Incidental diagnosis of a deep vein thrombosis in consecutive patients undergoing a computed tomography scan of the abdomen: a retrospective cohort study. J Thromb Haemost 2012;10:158-160.
9 Smalberg JH, Arends LR, Valla DC, Kiladjian JJ, Janssen HL, Leebeek FW: Myeloproliferative neoplasms in Budd-Chiari syndrome and portal vein thrombosis: a meta-analysis. Blood 2012;120:49214928.

10 Webster GJ, Burroughs AK, Riordan SM: Review article: portal vein thrombosis - new insights into aetiology and management. Aliment Pharmacol Ther 2005;21:1-9.

$>11$

Ponziani FR, Zocco MA, Garcovich M, D'Aversa F, Roccarina D, Gasbarrini A: What we should know about portal vein thrombosis in cirrhotic patients: a changing perspective. World J Gastroenterol 2012;18:5014-5020.

12 Janssen HL, Wijnhoud A, Haagsma EB, et al: Extrahepatic portal vein thrombosis: aetiology and determinants of survival. Gut 2001;49:720-724.

13 Tsochatzis EA, Senzolo M, Germani G, Gatt A, Burroughs AK: Systematic review: portal vein thrombosis in cirrhosis. Aliment Pharmacol Ther 2010;31:366-374.

14 Okuda K, Ohnishi K, Kimura K, et al: Incidence of portal vein thrombosis in liver cirrhosis. An angiographic study in 708 patients. Gastroenterology 1985;89:279-286.

15 Francoz C, Belghiti J, Vilgrain V, et al: Splanchnic vein thrombosis in candidates for liver transplantation: usefulness of screening and anticoagulation. Gut 2005;54:691-697.

16 Primignani M: Portal vein thrombosis, revisited Dig Liver Dis 2010;42:163-170.

17 Francoz C, Valla D, Durand F: Portal vein thrombosis, cirrhosis, and liver transplantation. J Hepatol 2012;57:203-212.
18 Kinjo N, Kawanaka H, Akahoshi T, et al: Portal vein thrombosis in liver cirrhosis. World $\mathrm{J}$ Hepatol 2014;6:64-71.

19 Zocco MA, Di Stasio E, De Cristofaro R, et al: Thrombotic risk factors in patients with liver cirrhosis: correlation with MELD scoring system and portal vein thrombosis development. J Hepatol 2009;51:682-689.

20 Amitrano L, Guardascione MA, Ames PR: Coagulation abnormalities in cirrhotic patients with portal vein thrombosis. Clin Lab 2007;53:583-589.

21 Kinjo N, Kawanaka H, Akahoshi T, et al: Risk factors for portal venous thrombosis after splenectomy in patients with cirrhosis and portal hypertension. Br J Surg 2010;97:910-916.

22 Bosch J, Garcia-Pagan JC: Complications of cirrhosis. I. Portal hypertension. J Hepatol 2000;32: 141-156.

23 Hennenberg M, Trebicka J, Sauerbruch T, Heller $\mathrm{J}$ : Mechanisms of extrahepatic vasodilation in portal hypertension. Gut 2008;57:1300-1314.

24 van't Riet M, Burger JW, van Muiswinkel JM, Kazemier G, Schipperus MR, Bonjer HJ: Diagnosis and treatment of portal vein thrombosis following splenectomy. Br J Surg 2000;87:1229-1233.

25 Amitrano L, Brancaccio V, Guardascione MA, et al: Inherited coagulation disorders in cirrhotic patients with portal vein thrombosis. Hepatology 2000;31:345-348.

26 Monroe DM, Hoffman M: The coagulation cascade in cirrhosis. Clin Liver Dis 2009;13:1-9.

27 Gatt A, Riddell A, Calvaruso V, Tuddenham EG, Makris M, Burroughs AK: Enhanced thrombin generation in patients with cirrhosis-induced coagulopathy. J Thromb Haemost 2010;8:1994-2000. 
28 Tripodi A, Mannucci PM: Abnormalities of hemostasis in chronic liver disease: reappraisal of their clinical significance and need for clinical and laboratory research. J Hepatol 2007;46:727-733.

29 Senzolo M, Cholongitas EC, Patch D, Burroughs AK: Update on the classification, assessment of prognosis and therapy of Budd-Chiari syndrome. Nat Clin Pract Gastroenterol Hepatol 2005;2:182190

30 Violi F, Ferro D, Basili S, et al: Ongoing prothrombotic state in the portal circulation of cirrhotic patients. Thromb Haemost 1997;77:44-47.

- 31 Tripodi A, Anstee QM, Sogaard KK, Primignani M, Valla DC: Hypercoagulability in cirrhosis: causes and consequences. J Thromb Haemost 2011; 9:1713-1723.

\32 Plessier A, Darwish-Murad S, Hernandez-Guerra M, et al: Acute portal vein thrombosis unrelated to cirrhosis: a prospective multicenter follow-up study. Hepatology 2010;51:210-218.

-33 Turon F, Cervantes F, Colomer D, Gaiges A, Hernández-Gea V, Garcia-Pagán JC: Role of calreticulin mutations in the etiological diagnosis of splanchnic vein thrombosis. J Hepatol 2014; DOI: 10.1016/j.jhep.2014.08.032.

34 Cohen J, Edelman RR, Chopra S: Portal vein thrombosis: a review. Am J Med 1992;92:173-182.

35 Condat B, Pessione F, Hillaire S, et al: Current outcome of portal vein thrombosis in adults: risk and benefit of anticoagulant therapy. Gastroenterology 2001;120:490-497.

-36 Lee SS, Ha HK, Park SH, Choi EK, Kim AY, Kim JC, Han DJ: Usefulness of computed tomography in differentiating transmural infarction from nontransmural ischemia of the small intestine in patients with acute mesenteric venous thrombosis. J Comput Assist Tomogr 2008;32:730-737.
37 DeLeve LD, Valla DC, Garcia-Tsao G; American Association for the Study of Liver Diseases: Vascular disorders of the liver. Hepatology 2009;49: 1729-1764.

38 Brunaud L, Antunes L, Collinet-Adler S, Marchal F, Ayav A, Bresler L, Boissel P: Acute mesenteric venous thrombosis: case for nonoperative management. J Vasc Surg 2001;34:673-679.

39 Condat B, Valla D: Nonmalignant portal vein thrombosis in adults. Nat Clin Pract Gastroenterol Hepatol 2006;3:505-515.

40 de Franchis R: Evolving consensus in portal hypertension. Report of the Baveno IV consensus workshop on methodology of diagnosis and therapy in portal hypertension. J Hepatol 2005;43:167-176.

41 Valla DC, Condat B: Portal vein thrombosis in adults: pathophysiology, pathogenesis and management. J Hepatol 2000;32:865-871.

42 Wiesner W, Khurana B, Ji H, Ros PR: CT of acute bowel ischemia. Radiology 2003;226:635-650.

43 Garcia-Pagan JC, Hernandez-Guerra M, Bosch J: Extrahepatic portal vein thrombosis. Semin Liver Dis 2008;28:282-292.

44 Amitrano L, Guardascione MA, Scaglione M, et al: Prognostic factors in noncirrhotic patients with splanchnic vein thromboses. Am J Gastroenterol 2007; 102:2464-2470.

45 Hoekstra J, Janssen HL: Vascular liver disorders (II): portal vein thrombosis. Neth J Med 2009;67: 46-53.
46 Sogaard KK, Astrup LB, Vilstrup H, Gronbaek H Portal vein thrombosis; risk factors, clinical presentation and treatment. BMC Gastroenterol 2007; 7 : 34.

47 Condat B, Vilgrain V, Asselah T, et al: Portal cavernoma-associated cholangiopathy: a clinical and MR cholangiography coupled with MR portography imaging study. Hepatology 2003;37:1302-1308.

48 Dhiman RK, Behera A, Chawla YK, Dilawari JB, Suri S: Portal hypertensive biliopathy. Gut 2007;56: 1001-1008.

49 Llop E, de Juan C, Seijo S, Garcia-Criado A, Abraldes JG, Bosch J, Garcia-Pagan JC: Porta cholangiopathy: radiological classification and natural history. Gut 2011;60:853-860.

50 Wanless IR, Liu JJ, Butany J: Role of thrombosis in the pathogenesis of congestive hepatic fibrosis (cardiac cirrhosis). Hepatology 1995;21:1232-1237.

51 Wanless IR, Wong F, Blendis LM, Greig P, Heathcote EJ, Levy G: Hepatic and portal vein thrombosis in cirrhosis: possible role in development of parenchymal extinction and portal hypertension. Hepatology 1995;21:1238-1247.

52 Englesbe MJ, Schaubel DE, Cai S, Guidinger MK Merion RM: Portal vein thrombosis and liver transplant survival benefit. Liver Transpl 2010;16: 999-1005.

53 Doenecke A, Tsui TY, Zuelke C, Scherer MN, Schnitzbauer AA, Schlitt HJ, Obed A: Pre-existent portal vein thrombosis in liver transplantation: influence of pre-operative disease severity. Clin Transplant 2010;24:48-55. 